\title{
FACTIVITY OR GROUNDS? COMMENT ON MIZRAHI
}

Howard SANKEY

\begin{abstract}
This note is a comment on a recent paper in this journal by Moti Mizrahi. Mizrahi claims that the factivity of knowledge entails that knowledge requires epistemic certainty. But the argument that Mizrahi presents does not proceed from factivity to certainty. Instead, it proceeds from a premise about the relationship between grounds and knowledge to the conclusion about certainty.
\end{abstract}

KEYWORDS: Moti Mizrahi, factivity, epistemic certainty, fallibilism, knowledge

In "You Can't Handle the Truth: Knowledge = Epistemic Certainty," Moti Mizrahi presents an argument for an infallibilist theory of knowledge. ${ }^{1}$ Mizrahi claims that the factivity of knowledge entails that knowledge is epistemic certainty. But the argument that Mizrahi presents does not in fact proceed from the factivity of knowledge to knowledge being epistemic certainty. Rather, the argument proceeds from an assumption about the relation between grounds and knowledge to the conclusion about epistemic certainty.

Mizrahi's argument is as follows:

1) If $S$ knows that $p$ on the grounds that $e$, then $p$ cannot be false given e.

2) If $\mathrm{p}$ cannot be false given e, then e makes $\mathrm{p}$ epistemically certain.

3) Therefore, if $\mathrm{S}$ knows that $\mathrm{p}$ on the grounds that e, then e makes $\mathrm{p}$ epistemically certain. ${ }^{2}$

As indicated, this argument begins with a premise about the grounds on which the knowing subject knows a proposition. But this is quite different from the claim that knowledge is factive. It is a claim about the relation between grounds (or evidence) and knowing.

More specifically, Mizrahi explains that: "To say that knowledge is factive is to say that, if $\mathrm{S}$ knows that $\mathrm{p}$, then $\mathrm{p}$ is true." In other words, knowledge is factive in the sense that knowledge requires truth. It is not possible to know a proposition if that proposition is false. Another way of stating the point is perhaps to say that

\footnotetext{
${ }^{1}$ Logos \& Episteme X, 2 (2019): 225-227.

${ }^{2}$ Mizrahi, "You Can't Handle the Truth," 225.
}

LOGOS \& EPISTEME X, 3 (2019): 333-334 
Howard Sankey

knowledge is sensitive to the facts. If what one purports to know gets the facts wrong, then one does not know.

Now it is important to notice that the claim that knowledge is factive says nothing about a relation between grounds and knowledge. All that is required for knowledge to be factive is that the item of knowledge in question be true. There is no mention here of grounds or evidence. The only thing relevant to factivity is truth.

This may only be a small point. But it does seem to show that it is not quite right to claim that the factivity of knowledge entails that knowledge is epistemic certainty. The work is being done, not by the factivity of knowledge, but by the relation between grounds and knowledge. 